\title{
Contrasting amounts of geographical variation as evidence for direct selection: the Mpi and Pgm loci in eight crustacean species
}

\author{
JOHN H. MCDONALD \\ Department of Ecology and Evolutionary Biology, Princeton University, Princeton, New Jersey 08544, USA
}

\begin{abstract}
At the Mpi locus in the amphipods Hyale plumulosa and Orchestia grillus, one allele in each species is less common inside six small bays on Long Island, New York, when compared with nearby exposed habitats on Long Island Sound. These consistently repeated differences in allele frequency could result from selection on the Mpi locus itself, or from selection on loci in linkage disequilibrium with $\mathrm{Mpi}$. When one exposed and one protected site were compared in $H$. plumulosa, $O$. grillus, and six other peracarid crustacean species, the $M p i$ locus exhibited greater between-site variation than the Pgm locus in all eight species. The consistently greater geographical variation in $M p i$ is unlikely to result from selection on linked loci, and indicates that selection results directly from the Mpi polymorphisms.
\end{abstract}

Keywords: allozymes, crustaceans, geographical variation, mannose-6-phosphate isomerase.

\section{Introduction}

Repeated differences in allele frequency between different habitats provide compelling evidence for natural selection on enzyme loci. In the amphipod Platorchestia platensis, the Mpi locus (coding for mannose6-phosphate isomerase, E.C. 5.3.1.8) exhibits repeated differences in allele frequency between habitats on Long Island, New York. Beaches exposed to Long Island Sound have higher frequencies of one $M p i$ allele than nearby beaches on small bays. These differences in allele frequency are more consistent in direction than expected from random drift, which indicates that the Mpi locus is affected by selection (McDonald, 1987). The first part of the present study reports on similar patterns of repeated differences in $M p i$ allele frequency in the amphipods Hyale plumulosa and Orchestia grillus, and provides further evidence that $\mathrm{Mpi}$ polymorphisms are affected by selection.

In common with other evidence for selection on enzyme loci, the repeated differences in $M p i$ allele frequency could be caused either by direct selection, resulting from the Mpi polymorphism itself, or indirect selection, resulting from loci in linkage disequilibrium with $M p i$. To distinguish between direct and indirect selection has long been a difficult problem in population genetics. The life histories of amphipods make indirect selection a particularly plausible explanation for geographical patterns of allele frequency. There is no planktonic larval stage; instead females carry their young in a brood pouch. Both the young and adults are poor swimmers, and each species' habitat is patchily distributed. Thus it is possible that populations are often founded by one or a few gravid females, which could easily result in substantial linkage disequilibrium. Long Island Sound, where these repeated patterns occur, is only a few thousand years old, which is a short enough time that any linkage disequilibrium generated in the original founders of Long Island Sound populations might not have broken down yet.

To test the possibility that geographical patterns at the $M p i$ locus result from loci in linkage disequilibrium, the variation in allele frequency was measured between two habitats for two loci, $\mathrm{Mpi}$ and $\mathrm{Pgm}$ (coding for phosphoglucomutase, E.C. 5.4.2.2). This comparison was made for eight species of peracarid crustaceans (seven amphipods and one isopod) that were polymorphic for both loci. If both loci were neutral markers whose geographical variation reflected only drift and selection on linked loci, the expectation is that half the species would exhibit greater between-site variation of $M p i$ allele frequencies, and half would exhibit greater variation of $\mathrm{Pgm}$ allele frequencies. If instead one locus exhibited consistently greater geographical variation than the other, it would be evidence of selection directly on one of the loci. The Pgm locus was chosen 
because it is polymorphic in many species of crustaceans (Hedgecock et al., 1982), including H. plumulosa and $O$. grillus. Unfortunately $\mathrm{Pgm}$ is monomorphic in $P$. platensis, so that species is not included in the comparison.

\section{Methods}

The Mpi locus was first sampled at several locations in the amphipod species Hyale plumulosa and Orchestia grillus. H. plumulosa was collected from the underside of rocks in the mid-intertidal area, and $O$. grillus was collected from beneath debris in the upper intertidal area of marshes. For each species, six pairs of locations were sampled on the north shore of Long Island, New York (Fig. 1). Each pair contained one 'protected' site, as far into a small bay as the species could be found, and one 'exposed' site. The exposed $H$. plumulosa sites faced the main body of Long Island Sound. Because $O$. grillus lives in marshy areas, its exposed sites are actually inside the small bays, as close to the mouth of each bay as the species can be found. The sites were paired in this way because the $M p i$ locus differs repeatedly in allele frequency between exposed and protected sites on Long Island in the amphipod Platorchestia platensis (McDonald, 1987). Because subjective, qualitative habitat classifications were used, it is important to emphasize that pairs of locations were chosen and their habitat types were assigned before the allozyme data were collected. The two sites in each pair were generally collected within a few days of each other. Electrophoresis was done with a tris-borateEDTA buffer, following McDonald (1987).
The Pgm and Mpi loci were then sampled in 12 amphipod and four isopod species. Species were identified using Schultz (1966), Bousfield (1973), and Conlan (1990). H. plumulosa, O. grillus, and six additional species of peracarid crustacean were polymorphic for both loci, and they were sampled at one exposed and one protected site (Fig. 1). The tris-maleic buffer of Koehn et al. (1984) was used for electrophoresis of these samples, because it gave good resolution of both MPI and PGM allozymes. MPI patterns were the same for $H$. plumulosa and $O$. grillus whether the tris-maleic or tris-borate-EDTA buffer was used. The few individuals for which one enzyme could not be scored were omitted, so that the sample sizes for both loci were the same within each location. Each gel contained individuals from both populations, and ambiguous individuals were run again. Individuals with rare alleles were rerun adjacent to each other. A polymorphic locus was defined as having the frequency of the common allele less than 0.95 in at least one sample. In order to detect any cryptic species, gels were also stained for peptidase, which has two or three isozymes, and glucose-6-phosphate isomerase. The total of five or six isozymes was sufficient to distinguish all the known pairs of species.

Geographical variation was measured with $\hat{F}_{\mathrm{ST}^{\prime}}(\mathrm{Nei}$, 1986), an estimator of Wright's $(1951) F_{\mathrm{ST}}$.

\section{Results}

There were two $M p i$ alleles in $H$. plumulosa. O. grillus had two common $M p i$ alleles and two rare alleles. The rare alleles had overall frequencies of 0.007 and 0.002 .

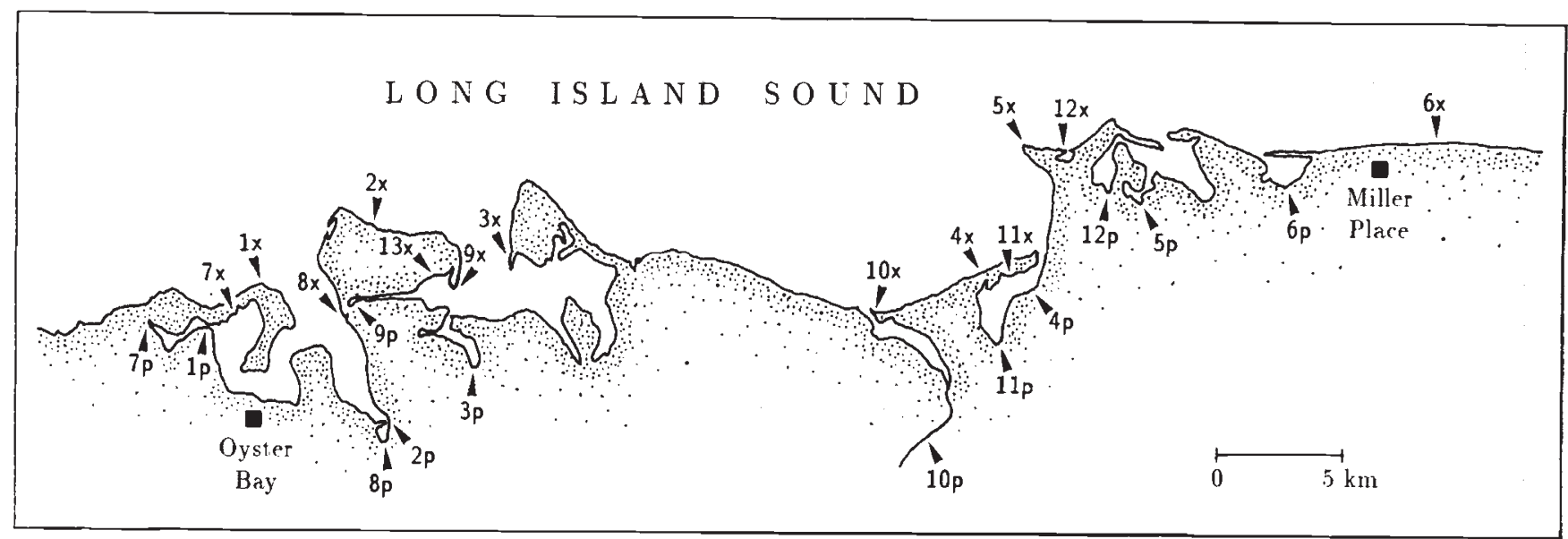

Fig. 1 Sample locations of peracarid crustaceans. For each pair of locations, ' $x$ ' indicates an exposed site and ' $p$ ' indicates a protected site. H. plumulosa was collected at pairs 1-6; O. grillus, pairs $7-12 ; G$. mucronatus, G. palustrus, J. marmorata and $M$. nitida, sites $2 \mathrm{x}$ and $3 \mathrm{p} ;$ E. triloba, sites $13 \mathrm{x}$ and $3 \mathrm{p}$; and $C$. acutum, sites $3 \mathrm{x}$ and $3 \mathrm{p}$. 
Allozymes were given letters in order of electrophoretic mobility, with the allozyme migrating furthest towards the anode in each species designated 'a'. Allozymes given the same letter in different species generally did not have the same mobility.

At all six pairs of $H$. plumulosa sample sites, the $M p i^{\mathrm{b}}$ allele was less common at the protected site than at the exposed site (Fig. 2a). This is significantly different from the null expectation (two-tailed sign test, $P=0.03$ ). A sign test (Sokal \& Rohlf, 1981, pp. $449-450)$ is appropriate because the null hypothesis is that any one pair of locations might differ in allele frequency due to random drift, but the direction of differences would be random when several pairs of locations were examined. At all six pairs of $O$. grillus sample sites, the $M{ }^{\mathrm{b}}{ }^{\mathrm{b}}$ allele was less common at the protected site (Fig. $2 b$ ), which is significantly different from the null expectation (sign test, $P=0.03$ ).

$\mathrm{Mpi}$ and Pgm were sampled initially in 12 species of amphipod and four species of isopod. Seven amphipod species (Corophium acutum, Gammarus mucronatus, Gammarus palustrus, Hyale plumulosa, Jassa marmorata, Melita nitida and Orchestia grillus) and one
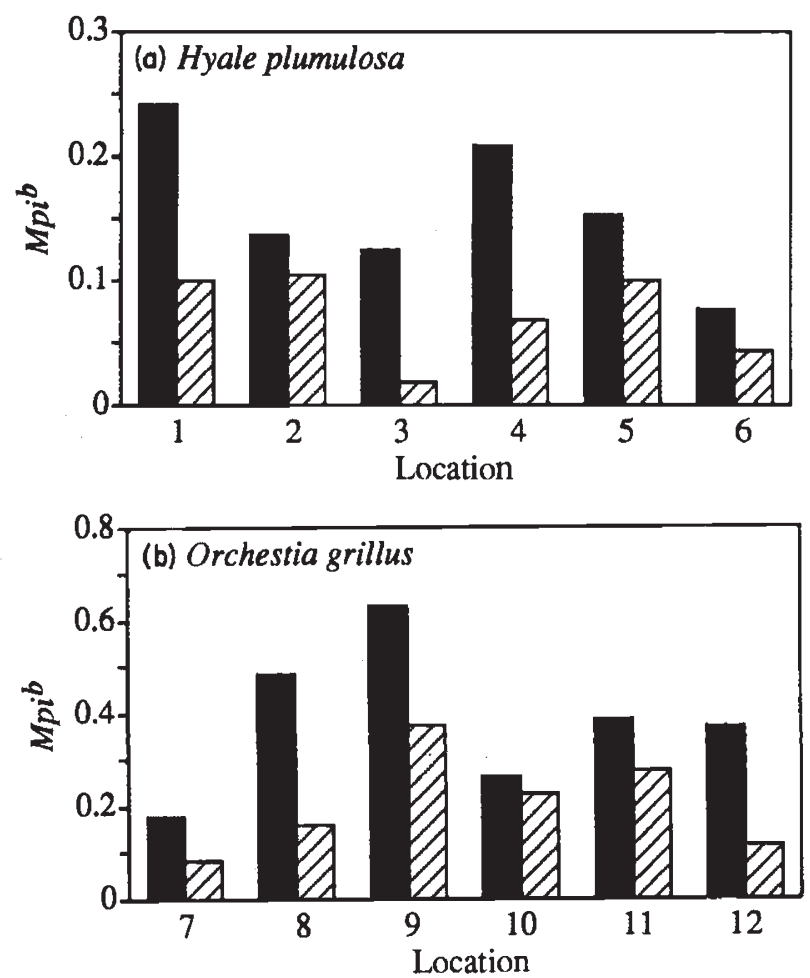

Fig. 2 Repeated differences in $M p i$ allele frequency in $H$. plumulosa and $O$. grillus. Mpi allele frequencies are given for the locations shown in Fig. 1. Each species had two common alleles, with two additional rare alleles in $O$. grillus. The solid bar represents the exposed beach for each pair of locations, and the striped bar represents the protected beach. isopod (Edotia triloba) were polymorphic for both $\mathrm{Mpi}$ and Pgm and could be found in both a protected harbour and a more exposed area (Fig. 1). All eight species had a greater $\hat{F}_{\mathrm{ST}^{\prime}}$ for $M p i$ than for Pgm (Table $1)$, which is significantly different from the null expectation that each locus should have a greater $\hat{F}_{\mathrm{ST}^{\prime}}$ in half the species (two-tailed sign test, $P=0.008$ ). When locations for $H$. plumulosa and $O$. grillus were chosen the geographical variation in $\mathrm{Pgm}$ had not yet been sampled, but it was known that the locations differed greatly in $M p i$ allele frequency. It may therefore be preferable to exclude these species from the statistical test. The deviation from the null expectation in the remaining six species is still significant (twotailed sign test, $P=0.03$ ).

\section{Discussion}

In the amphipods $H$. plumulosa and $O$. grillus, one $M p i$ allele is consistently less common in protected habitats inside small bays on Long Island than in exposed habitats outside or near the mouths of the small bays. A similar pattern is present in the amphipod P. platensis (McDonald, 1987). Because the differences in allele frequency are significantly more consistent in direction than would be expected from random drift, they are evidence that selection affects the $M p i$ polymorphism in each species.

The repeated differences in $M p i$ allele frequency between habitats in $H$. plumulosa and $O$. grillus could result from selection directly on $\mathrm{Mpi}$, or from selection on loci with which $M p i$ is in linkage disequilibrium. The sampling of Mpi and Pgm in eight species was an attempt to distinguish between direct and indirect selection. If $\mathrm{Mpi}$ and $\mathrm{Pgm}$ are neutral markers whose geographical variation reflects only drift and selection on linked loci, the expectation is that in some species $P g m$ would exhibit greater geographical variation than $M p i$, and in some species $M p i$ would exhibit greater geographical variation than Pgm. That $M p i$ has greater geographical variation than $\mathrm{Pgm}$ in all eight species indicates that direct selection affects these loci. This pattern, in combination with the repeated geographical differences in $\mathrm{Mpi}$ allele frequency between habitats in $H$. plumulosa and $O$. grillus, suggests that the direct selection is differentiating selection on $\mathrm{Mpi}$, and not stabilizing selection on Pgm.

A key assumption of this interpretation is that $M p i$ is not in linkage disequilibrium with a similarly selected set of loci in all the species. The eight species of crustaceans sampled here are divided into two orders (one isopod and seven amphipods), five superfamilies, and seven families (Bousfield, 1973, 1983); the two cogeners, G. mucronatus and $G$. palustrus, occupy 
Table $1 \hat{\mathrm{ST}}^{\prime}$ and allele frequencies of $\mathrm{Mpi}$ and $\mathrm{Pgm}$ in eight species of peracarid crustaceans. Mpi and Pgm allele frequencies were sampled at the locations shown in Fig. 1. Sites $2 \mathrm{x}$ and $3 \mathrm{p}$ were used for H. plumulosa, and sites $8 \mathrm{x}$ and $8 \mathrm{p}$ were used for $O$. grillus. For each pair of locations, ' $x$ ' indicates an exposed site and ' $p$ ' indicates a protected site. $N$ is the number of individuals. Alleles are listed in order of the electrophoretic mobility of their products, with ' $a$ ' coding the fastest allozyme in each species. Allozymes given the same letter in different species generally have different mobilities

\begin{tabular}{|c|c|c|c|c|c|c|c|c|c|c|c|c|}
\hline \multirow[b]{2}{*}{ Species } & \multirow[b]{2}{*}{ Locus } & \multirow[b]{2}{*}{$\hat{F}_{\mathrm{ST}^{\prime}}$} & \multirow[b]{2}{*}{ Site } & \multirow[b]{2}{*}{$N$} & \multicolumn{8}{|l|}{ Allele } \\
\hline & & & & & $a$ & $b$ & $c$ & $d$ & $e$ & $f$ & $g$ & $h$ \\
\hline \multirow[t]{4}{*}{ C. acutum } & $M p i$ & 0.006 & $\mathrm{x}$ & 95 & 0 & 0.132 & 0.089 & 0.537 & 0.195 & 0.037 & 0.011 & 0 \\
\hline & & & $\mathrm{p}$ & 84 & 0.012 & 0.089 & 0.167 & 0.458 & 0.232 & 0.036 & 0.006 & 0 \\
\hline & $P g m$ & -0.001 & $\mathrm{x}$ & 95 & 0.016 & 0.032 & 0.868 & 0.084 & 0 & 0 & 0 & 0 \\
\hline & & & $p$ & 84 & 0.012 & 0.060 & 0.827 & 0.101 & 0 & 0 & 0 & 0 \\
\hline \multirow[t]{4}{*}{ E. triloba } & $M p i$ & 0.032 & $\mathrm{x}$ & 83 & 0.018 & 0.139 & 0.355 & 0.361 & 0.096 & 0.030 & 0 & 0 \\
\hline & & & $\mathrm{p}$ & 56 & 0.062 & 0.286 & 0.375 & 0.179 & 0.054 & 0.036 & 0.009 & 0 \\
\hline & $P g m$ & -0.004 & $\mathrm{x}$ & 83 & 0.012 & 0.048 & 0.488 & 0.422 & 0.030 & 0 & 0 & 0 \\
\hline & & & $\mathrm{p}$ & 56 & 0.009 & 0.036 & 0.536 & 0.384 & 0.027 & 0.009 & 0 & 0 \\
\hline \multirow[t]{4}{*}{ G. mucronatus } & $M p i$ & 0.009 & $\mathrm{x}$ & 127 & 0 & 0.043 & 0.220 & 0.303 & 0.232 & 0.177 & 0.020 & 0.004 \\
\hline & & & $\mathrm{p}$ & 125 & 0.016 & 0.056 & 0.180 & 0.288 & 0.344 & 0.108 & 0.008 & 0 \\
\hline & Pgm & 0.001 & $\mathrm{x}$ & 127 & 0.016 & 0.028 & 0.063 & 0.551 & 0.268 & 0.067 & 0.008 & 0 \\
\hline & & & $\mathrm{p}$ & 125 & 0.020 & 0.028 & 0.080 & 0.492 & 0.312 & 0.068 & 0 & 0 \\
\hline \multirow[t]{4}{*}{ G. palustrus } & $M p i$ & 0.008 & $x$ & 89 & 0.197 & 0.489 & 0.303 & 0.011 & 0 & 0 & 0 & 0 \\
\hline & & & $\mathrm{p}$ & 96 & 0.083 & 0.526 & 0.333 & 0.057 & 0 & 0 & 0 & 0 \\
\hline & Pgm & -0.004 & $\mathrm{x}$ & 89 & 0.017 & 0.084 & 0.112 & 0.764 & 0.017 & 0.006 & 0 & 0 \\
\hline & & & $p$ & 96 & 0.026 & 0.089 & 0.135 & 0.734 & 0.016 & 0 & 0 & 0 \\
\hline \multirow[t]{4}{*}{ J. marmorata } & $M p i$ & 0.012 & $\mathrm{x}$ & 119 & 0 & 0.067 & 0.458 & 0.403 & 0.050 & 0.021 & 0 & 0 \\
\hline & & & $p$ & 73 & 0.007 & 0.055 & 0.575 & 0.322 & 0.041 & 0 & 0 & 0 \\
\hline & $P g m$ & 0.005 & $\mathrm{x}$ & 119 & 0 & 0.046 & 0.765 & 0.109 & 0.071 & 0.008 & 0 & 0 \\
\hline & & & $\mathrm{p}$ & 73 & 0.007 & 0.041 & 0.829 & 0.089 & 0.021 & 0.014 & 0 & 0 \\
\hline \multirow[t]{4}{*}{ M. nitida } & $M p i$ & 0.034 & $\mathrm{x}$ & 88 & 0.017 & 0.949 & 0.034 & 0 & 0 & 0 & 0 & 0 \\
\hline & & & $\mathrm{p}$ & 83 & 0 & 1.000 & 0 & 0 & 0 & 0 & 0 & 0 \\
\hline & $P g m$ & -0.001 & $\mathrm{x}$ & 88 & 0.006 & 0.920 & 0.074 & 0 & 0 & 0 & 0 & 0 \\
\hline & & & $\mathrm{p}$ & 83 & 0.024 & 0.886 & 0.090 & 0 & 0 & 0 & 0 & 0 \\
\hline \multirow[t]{4}{*}{ H. plumulosa } & $M p i$ & 0.113 & $\mathrm{x}$ & 96 & 0.828 & 0.172 & 0 & 0 & 0 & 0 & 0 & 0 \\
\hline & & & $\mathrm{p}$ & 66 & 0.977 & 0.022 & 0 & 0 & 0 & 0 & 0 & 0 \\
\hline & Pgm & 0.009 & $\mathrm{x}$ & 96 & 0.042 & 0.729 & 0.229 & 0 & 0 & 0 & 0 & 0 \\
\hline & & & $\mathrm{p}$ & 66 & 0.045 & 0.644 & 0.311 & 0 & 0 & 0 & 0 & 0 \\
\hline \multirow[t]{4}{*}{ O. grillus } & $M p i$ & 0.374 & $\mathrm{x}$ & 63 & 0.008 & 0.556 & 0.032 & 0.405 & 0 & 0 & 0 & 0 \\
\hline & & & $\mathrm{p}$ & 76 & 0 & 0.099 & 0.013 & 0.888 & 0 & 0 & 0 & 0 \\
\hline & Pgm & 0.002 & $\mathrm{x}$ & 63 & 0.087 & 0.159 & 0.611 & 0.087 & 0.056 & 0 & 0 & 0 \\
\hline & & & $p$ & 76 & 0.118 & 0.158 & 0.520 & 0.138 & 0.066 & 0 & 0 & 0 \\
\hline
\end{tabular}

separate subgenera (Barnard \& Gray, 1968). It is possible that a linkage group containing $M p i$ has been conserved throughout these higher taxa, but an explanation of the consistently greater $F_{\mathrm{ST}}$ of $\mathrm{Mpi}$ would require the following: that the linkage group was conserved; that the linkage group containing $\mathrm{Mpi}$ also contained selected loci; that the selected loci were polymorphic in all eight species; that the selected polymorphic loci in that linkage group experienced differentiating selection between habitats in all eight species; and that linkage disequilibrium between $M p i$ and the polymorphic selected loci was generated through hitchhiking or drift in all eight species. While this concatenation of circumstances cannot be completely ruled out, direct selection on the Mpi polymorphisms is a more parsimonious explanation.

One locus can have a consistently greater number of alleles than a second locus, either due to a greater neutral mutation rate or a better electrophoretic resolution. This would be a serious problem for the test presented here if the number of alleles had a large effect on the $F_{\mathrm{ST}}$ expected under random drift. Preliminary simulations suggest that if one locus averages many more alleles than a second locus, the locus with more alleles would be expected to have a greater $F_{\mathrm{ST}}$ in only slightly more than half the species (J. $\mathrm{H}$. McDonald, unpublished observations). Fortunately, the average number of alleles is virtually identical for $\mathrm{Mpi}$ 
(5.1 alleles) and $\operatorname{Pgm}$ (5.0 alleles) in the eight species studied here.

This test is somewhat reminiscent of the test proposed by Lewontin \& Krakauer (1973), which assumes that it would be unlikely for neutral loci within one species to vary greatly in their amount of geographical variation. Their test requires that the populations sampled are independent, an assumption that is rarely met (Nei \& Maruyama, 1975; Robertson, 1975). In the test proposed here, it is not the size of the variance in geographical variation among loci within one species that is evidence of selection, but instead the observation that one locus exhibits consistently greater geographical variation than another in several species.

The eight species in which $M p i$ has greater betweensite variation than Pgm live in a variety of microhabitats, including under debris at the high tide line, under rocks in the mid- or lower intertidal, buried in mud, and in tubes on submerged objects. The species occupy a number of feeding guilds, including suspension feeding, deposit feeding, grazing on attached microfauna and flora, and detritus foraging. There are many environmental factors which may differ between exposed and protected habitats, but the generality of selection on Mpi suggests that the selective factor on $M p i$ is a physical factor which affects a wide variety of marine species.

\section{References}

BARNARD, J. L. AND GRAY, w. S. 1968. Introduction of an amphipod crustacean into the Salton Sea, California. Bull. South. Calif. Acad. Sci., 67, 219-232.
BOUSFIELD, E. L. 1973. Shallow-water Gammaridean Amphipoda of New England. Cornell University Press, Ithaca, NY.

BoUSFIELD, E. L. 1983. An updated phyletic classification and paleohistory of the Amphipoda. In: Schram, F. R. (ed.), Crustacean Phylogeny, A. A. Balkema, Rotterdam, pp. 257-277.

CONLAN, K. E. 1990. Revision of the crustacean amphipod genus Jassa Leach (Corophioidea: Ischyroceridae). Can.J. Zool., 68, 2031-2075.

HEDGECOCK, D., TRACEY, M. L. AND NELSON, K. 1982. Genetics. In: Abele, L. G. (ed.), The Biology of Crustacea: Embryology, Morphology, and Genetics, Academic Press, New York, pp. 283-403.

KOEHN, R. K., HALL, J. G., INNES, D. J. AND ZERA, A. J. 1984. Genetic differentiation of Mytilus edulis in eastern North America. Mar. Biol., 79, 117-126.

LEWONTIN, R. C. AND KRAKAUER, J. 1973. Distribution of gene frequency as a test of the theory of the selective neutrality of polymorphisms. Genetics, 74, 175-195.

MCDONALD, J. H. 1987. Repeated geographic variation at three enzyme loci in the amphipod Platorchestia platensis. Evolution, 41, 438-441.

NEI, M. 1986. Definition and estimation of fixation indices. Evolution, 40, 643-645.

NEI, M. AND MARUYAMA, T. 1975. Lewontin-Krakauer test for neutral genes. Genetics, 80, 395 .

ROBERTSON, A. 1975. Remarks on the Lewontin-Krakauer test. Genetics, 80, 396.

schultz, G. A. 1966. How to Know the Marine Isopod Crustaceans. W. C. Brown, Dubuque.

SOKAL, R. R. AND ROHLF, F. J. 1981. Biometry. W. H. Freeman, San Francisco.

WRIGHT. s. 1951 . The genetical structure of populations. Ann. Eugen., 15, 323-354. 